Moroesi R. Nakin \&

Inie J. Kock

Rosalia Moroesi Nakin is a senior lecturer in Sesotho at the University of South Africa, specialising in sociolinguistics.

Email:nakinrm@unisa.ac.za Inie J. Kock is affiliated with the University of South Africa, specialising in the study of language in literature. Email: inie.k@mweb.co.za

\section{Insights into translation and the original text: Thomas Mofolo's Chaka}

\title{
Insights into translation and the original text: Thomas Mofolo's Chaka
}

This paper aims to explore the strategies applied during the translation of chosen passages from the original Sesotho text of Chaka by Thomas Mofolo into English. Insights expressed here originate from participation in the translation workshops during the conference on "Translating Mofolo". Different stages of the translation process are identified and discussed, while the main emphasis is placed on resolving instances of non-equivalence between the source text and the target text. Non-equivalence includes among other things, culture-specific words and expressions in the source language, grammatical considerations in both the source text and the target text, and the relationship between linguistic units in context. Culture specific words and expressions relate to idiomatic expressions and fixed combinations of words in the source and target texts. Grammatical considerations refer to the translation of Sesotho-specific moods and tenses, number, person, etc., into English, while the relationship between linguistic units is discussed with regard to cohesion, reference and other related cohesive devices in context. Keywords: cultural specificity, non-equivalence, Thomas Mofolo, translation strategies.

\section{Introduction}

Language users comprehend and describe the world and their reality in their own individual ways. While language is perceived as an integral part of culture, culture itself may be defined as "the way of life and its manifestations that are peculiar to a community that uses a particular language as a means of expression" (Newmark 94). Each language group therefore has its own culturally specific characteristics that feature within its own language, and that is the reason why, during translation, no two languages can be expected to be word-for-word interchangeable. The role culture plays in the production of any acceptable translated text is crucial: this principle will be illustrated in this article.

The decision was made to implement a descriptive approach towards this short study of translating Mofolo's Chaka. Although a great deal of research has been done in an attempt to categorise and structuralise translation studies (see Nida and Taber), the descriptive translation theory suits the purpose of translation studies more adequately. The descriptive theory focuses on "fieldwork" or the examination of texts together with their translation(s), and then progresses to a description of the principles and limitations experienced by translators within a specific culture at a given historical time. Closely linked to the descriptive translation theory is the 
functionalist approach to translation, which studies the function of texts-the source text (ST) and the target text (TT) - and does not aim for equivalence between texts and their translations (Wallmach and Kruger 278). As Bassnett states: “... exact reproduction is impossible, since the worlds in which the original text and its translation are produced are inevitably different worlds. The task of the translator is therefore to mediate between those two different moments in time and space, and to produce a text that exists in a relationship with both" (1). Nida and Taber stress the importance of focusing on "the response of the receptor to the translated message" (1). These are the translation concepts that this article will focus on.

The aim of this article is to illustrate how a process of translation may be enacted, and to explain the different stages in its production. It will be shown how the eventual product of this process truly may be identified as the "fruit and historical consequence of the translator's relationship with the original" (Bassnett 2). This process is recognised by Terran who acknowledges that "it is only in the recognition and careful evaluation of all the intervening variables that translation studies can honestly make any progress" (36).

The translation of our text stems from the "Translating Mofolo" conference which was held in Roma, Lesotho, in March 2015, which included two translation workshops, set two days apart. During the first workshop, the Translation Initiator (or TI), Antjie Krog, requested conference participants to form three teams in order to translate the original Sesotho text into English. The chosen extracts from the original Sesotho text were page 38 (where Chaka and Isanusi, the medicine man, have a conversation about what Chaka desires from life that Isanusi could assist him to achieve) and page 45 (where Chaka's change in personality is described, when he returned to Dingiswayo's home after being treated by Isanusi).

The workshop groups consisted of approximately five to eight participants, made up of mother-tongue as well as second (and third) language speakers of Sesotho. In line with the TI's instructions we notated all suggested variations of English words and utterances, and in so doing accumulated a corpus of words and combination of words (sometimes up to six variants were offered) from which ultimately to choose the ideal or most appropriate translation. During the second translation workshop the following day, we attempted to finalise our translations, but realised we probably would need another translation session, as it still proved difficult to finalise specific words and utterances. What also complicated the final workshop is the fact that more participants were added to the teams from the previous day, and participants changed groups, which, as one could expect, implied that even more words were added to the existing corpus.

The translation workshops were thus executed within a specific framework of set priorities and restrictions laid out by the TI. The workshop's findings were inconclusive as to a final translation, but the valuable insights gained from the translation workshops informed the translations in this article. 
Firstly, the original ST was divided into smaller semantic units. Then, the corpus of variants for the TT were sorted with each semantic unit in the ST, and each variant was indicated with a superscript number. This provides the opportunity for considering and deciding on the best variant per semantic unit during the final stage of translation. In the third step, semantically complex units are discussed and explained. It will be shown how important the sociolinguistic background of our ST proves to be in order to arrive at the final translation. Final translations of the chosen extracts are presented and finally, strategies applied during translation are discussed.

During steps 1 and 2 the ST is divided into smaller semantic units with the corpus of variants added, which is indicated with a superscript number. It is necessary to combine step 1 and 2 in order to illustrate in a more adequate way how the ST and the TT differ. Semantically complex units are indicated with an asterisk.

\section{Extract 1: The dialogue (38-39)}

"Jwale mpolelle ditakatso tsa pelo ya hao ("Now tell me what the desires $1 /$ yearnings $^{2}$ of your heart are);

le seo o ratang hore hara ntho tsohle (and that which you desire amongst all things $\mathrm{s}^{1} /$ more than anything else $\left.{ }^{2}\right)$;

*ke bee melamu ho sona" ${ }^{*}\left[\right.$ so] that I should lay my stick(s) $/ /$ kierie $(\mathrm{s})^{2} /$ staff(s) ${ }^{3} /$ concentrate $^{4}$ my skills on it");

"Ha ke na ditakatso tse ngata, *pelo ya ka e llela ("I don't have many desires *my heart cries for $1 /$ yearns for $2 /$ longs for $\left.{ }^{3}\right)$;

borena ba ka boo ke bo tswaletsweng (my kingship for/to which I was born ${ }^{1 /}$ is my birthright ${ }^{2} \mathrm{I}$ have inherited $\left.{ }^{3}\right)$;

*bo tla mphonyoha $\left({ }^{*}\right.$ It will evade $\mathrm{me}^{1 /}$ escape $\mathrm{me}^{2 / I}$ will lose it $\left.{ }^{3}\right)$;

feela ka hobane *ke mpa ke le senyo (Only because *I just am in trouble ${ }^{1 / a m}$ unlucky ${ }^{2}$ have bad luck ${ }^{3 / a m}$ hated by people ${ }^{4 / a m}$ unpopular ${ }^{5}$ );

Ke re (I say ${ }^{1 /}$ mean $\left.^{2}\right)$;

*o ntshebetse hore borena boo bo mpoele" (*you must treat $1 /$ labour on $2 /$ work on $3 /$ anoint ${ }^{4}$ me so that that kingship returns to me");

"Ke a utlwa ("I hear ${ }^{1}$ understand ${ }^{2}$ );

o batla borena ba ntatao feela, ho feta moo ha o batle letho, le borena bo fetang ba ntatao ha o bo batle; ha ke re o rialo?" (You only want the kingship of your father, do you have no desire apart from that, even a kingship greater than that ${ }^{1 /}$ that surpasses that of your father ${ }^{2}$; do you not want to seek it; is it not true that you said so?");

"Tjhe, ke a bo batla. ("No, I do want it.);

Ha eba o ka etsa hore ke be morena e moholo, ya ipusang, eo marenana a mang a kgotsitseng ho yena, nka leboha haholo. (If it is possible that you can make $\mathrm{enable}^{2} \mathrm{me}$ to become an important king, one that rules independently, such a one who will cause other less important kings to seek refuge with him, I will be very grateful.); 
Empa, ngaka, o mpolelle nnete ya seo o ka se etsang; hangata dingaka le tshepisa batho mehlolo, ntho tseo le tsebang hantle hore le ke ke la ba la di etsa." (But, doctor, you must tell me the truth about that which you are able to do; often doctors make people hope for miracles, those things they know well enough that they are not able to do.");

"O kgolwe ke nna, nke ke ka o thetsa ("You should believe in me, I will not lie to you);

Taba tsa lefatshe, ke a kgolwa, hanyenyane o se o di bone (The things of the earth, I believe, of which you have seen only a little);

hore ho phelwa ka leeme le ka lerato (that it should be lived with partiality ${ }^{1} /$ privileges $^{2}$

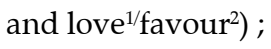

ka lonya le ka dikgoka (with wickedness ${ }^{1 /}$ cunningness $^{2}$ and with force ${ }^{1 / \mathrm{Control}^{2}}$ );

mme le wena mohau o kgaohane le wona (and even you, with mercy, you should part with ${ }^{1 /}$ have to part with $2 /$ give up ${ }^{3}$ mercy);

ho tloha tsatsing lena (as from this day forward);

hobane * mohau o ja mong a wona (because mercy does eat ${ }^{1 /}$ devours ${ }^{2 /}$ destroys ${ }^{3}$ its owner/a good deed is returned by evil $\left.{ }^{4}\right)$;

Hape nke ke ka dula halele ho wena; ke tla sebetsa, ebe ke a tsamaya, o sale o itshebeletsa borena boo o bo batlang." (Furthermore, I cannot stay with you much longer; I will work on you, and then I will leave, so that you can remain behind and you yourself labour at

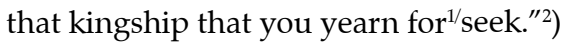

One of the major differences between Sesotho and English is the word order. A comparison between the Sesotho sentences above and literal English translations thereof will adequately illustrate the difference. The asterisks in the texts indicate some of the most problematic utterances, which will be discussed in further detail.

Firstly there is the sentence, "Now tell me the desires of the heart of you, and that which you want that amidst all things I should lay the staff(s) on it". A better translation into English would be: "Now tell me what the desires of your heart are, and that which you desire amongst all things so that I should lay my staff on it."

Also compare the word order of mme le wena mohau o kgaohane le wona (and also you, mercy, you should part with it). The better English translation is: "and even you, you should give up mercy". It became clear that the word order of Sesotho and that of English differs to such a degree that it would have to be a major consideration during the translation process.

Words in Sesotho that posed a challenge for translation because they do not exist in English, for example the word molamu, needed more explanation with regard to their function in the ST in order to find a suitable English word for them. A molamu is a stick or kierie (in Afrikaans), which is a walking stick, but it may also be used for a weapon. The use of the plural of molamu, i.e. melamu (more than one staff), here indicates more than just a staff; it also includes the medicine Isanusi will administer to Chaka, for example medicine to make him fierce, brave, heartless, etc. The term 
molamu may also refer to the skills of Isanusi. Most people belonging to the Basotho nation would know these facts about the term. For an Afrikaans and English speaker, the only context the word molamu may fit in is the historical use of a staff by e.g. the Israelites in the Bible to effect the occurrence of miracles. Therefore, it seemed the best word to use in the English translation.

There are other expressions in Sesotho also containing the word molamu, for example, ho bea molamu fatshe, literally translated, "to put the stick on the ground", and idiomatically translated, "to throw in the towel, to give up". The word molamu should be perceived as an important object in the Basotho culture, not only in the time that Chaka lived, but today still, as it remains an important cultural artefact, used in most cultural activities of the Basotho and worn as part of the cultural attire of the people. Together with the molamu, any Mosotho man will also wear a modianyewe (a Basotho hat) and a kobo (a Basotho blanket) to any cultural gathering of importance. The molamu has been part of the socio-cultural background of the Basotho for a very long time. In a sketch of King Moshweshwe the First (Casalis 15) the king is portrayed holding a molamu.

One of the qualifying features of a Mosotho man is the molamu. A molamu signifies the authority and the power that a man has. A Mosotho man has to protect and fight for his family, he has to defend his territory, which is why the molamu symbolises readiness to separate an enemy from a friend. It is believed that a Mosotho man has to use his molamu as a supporting pillar when in deep thought. Even when a Mosotho man is moving within the village, the molamu will be used to frighten the village dogs. The very significance of the molamu is to break, to protect, to judge and to rectify social injustices.

The modianyewe (the hat of casting-down-a-case/taken to court for justice/cause of a quarrel) is the typical cone-shaped Basotho hat, which was designed to resemble the mountains where Moshweshwe the First lived when he defeated the various nations that were attacking the Basotho. Moshweshwe is also known for the fact that he offered the attacking forces who lost a battle with the Basotho the opportunity to remain behind and become one with the Basotho nation, thus offering asylum to his enemies. The word literally means "causing the case to fall", a sign of peaceful judgement, one characterised by fairness from the king.

As regards the kobo (blanket), there are different kinds of blankets used by the Basotho. A blanket simply signifies warmth. The importance of the Basotho blanket is illustrated in the variety of proverbs and idiomatic expressions in Sesotho in which the word occurs. For example, kobo e sehellwa hodima kobo e nngwe (literally translated as "the blanket is cut up on top of another blanket"). This is a proverb describing the wisdom of imitation. Ho amohela morena, le kobo ya hae, le dinta tse ho yona can be literally translated as "to accept the chief, and his blanket, and the human lice in it" and figuratively as "to receive under protection the chief, his land and people". 
Other Sesotho expressions from Extract 1 illustrate differences between Sesotho and English words and their literal and figurative meanings, for instance bo tla mphonyoha whose literal translation is "it will escape me", but can be figuratively translated as "I will lose it". The phrase *ke mpa ke le senyo is literally translated as "* I only am in a sinking place", but the figurative meaning is "I only have bad luck". The word "senyo means "bad luck", and as an adjective "unpopular" or "unlucky". It is an archaic word which is not often used, originating from the ideophone nyoto (to go down, to sink), from which the noun senyo(to) has been derived. The utterance *O ntshebetse hore borena boo bo mpoele." means "You must work on me so that that kingship returns to me", but the figurative translation goes further to suggest it must read "You must treat me with medicine". Finally, the phrase *mohau o ja mong a wona literally means "mercy eats its owner". A figurative translation would be "a good deed is returned by evil".

\section{Extract 2: The discourse (45)}

Chaka, mohla a tlohang hae ha a baleha (Chaka, the day he left home ${ }^{1 /}$ his home $2 /$ that Chaka left his own home ${ }^{3}$, when he ran away ${ }^{1} /$ in flight $^{2}$ );

o tlohile e le Chaka (he left being that Chaka ${ }^{1} /$ he left as Chaka ${ }^{2} /$ being Chaka ${ }^{3}$ );

e le motho ya jwale ka batho bohle (he was a person just like all other people ${ }^{1 / l i k e ~ e v e r y-~}$ body else ${ }^{2}$ );

ya nang le mefokolo ya botho (who has weaknesses of being human $1 /$ a human being $2 /$ humaneness ${ }^{3} /$ humanity $^{4} /$ with all the human weaknesses ${ }^{5}$ );

kajeno o kgutla a fetohile hampe (today he returns as a changed ${ }^{1} / e^{2}$ tremely changed person $^{2} /$ different person from what he was $3 /$ having changed terribly ${ }^{4} /$ for the worst 5 / an extremely disgraced person $\left.{ }^{6}\right)$;

ho kgutla nama feela, bokantle (only the flesh returned, the outside);

ha e le boyena (with regard to his inner self $1 /$ the self of him²);

bo setse moo a tswang teng (it remained where he came from ${ }^{1} /$ his being is left where he came from ${ }^{2}$ );

o kgutla ka moya osele le ka botho bosele (he returns with a different spirit and a different humanity $1 /$ character $^{2} /$ personality $\left.^{3}\right)$;

Le pele Chaka e ne e le motho ya leqophe ka mokgwa o makatsang (Even before, Chaka was a person in a persistent $t^{1} /$ astonishing $^{2} /$ surprising way $^{3} /$ he was astonishingly determined $^{4}$ ); o ne a pheella leha ho le boima *jwang le jwang, a be a yo fihla *qetellong ya ditaba (He was persistent, though it was difficult, until he reached the end $1 /$ he was persistent until he reached the bottom of the matter $\left.{ }^{2}\right)$;

${ }^{*} k_{\text {g }}$ utlong ya merero ya pelo ya hae (At the return of $1 /$ In returning to ${ }^{2} /$ to attain $3 /$ his heart's desire $^{1} /$ plans of his heart ${ }^{2}$ );

ho se letho le ka mo thibang ho phetha seo a se hopotseng (there was nothing that could keep him from fulfilling that which he had in his mind $^{1 /}$ there was nothing that could stop 
him from doing what was on his $\operatorname{mind}^{2} /$ fulfilling his wishes $\left.{ }^{3}\right)$;

empa leha ho le jwalo e ne e le motho (but although it was so, he was human $1 /$ nevertheless he was human');

a se leqhoko (he was not seeking quarrels ${ }^{1} /$ quarrel poking $^{2} /$ quarrelsome $^{3}$ );

a sa tsebe *ho e lata letailane. (he would not go a long way to start a fight $1 /$ he would not go out of his way to start a fight ${ }^{2}$ );

Kajeno ha a bona bana ba ntatae ba mmolaela lefeela, a bona ntatae a iphetola sera sa hae, a baleha, mme *ha a le feelleng koo, boyena ba eshwa (Today when he sees his siblings killing him for nothing, he notices that his father changes into his enemy, [and then] he fled.

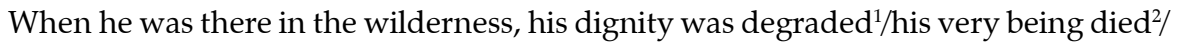
the core of his being $\left.\operatorname{died}^{3}\right)$;

kajeno o kgutla ka moya ona: (today, he comes back with this attitude $1 /$ spirit $^{2}$ :);

"Ke tla bolaya feela eo ke ratang ho mmolaya ("I will just kill anyone I want to kill1/whoever I would like to kill²);

a leng molato kapa a se nang wona (the one who is guilty or not $1 /$ whether guilty or not' hobane ke wona molao wa lefatshe. (because that is the rule of the world ${ }^{1} / \mathrm{earth}^{2} /$ that $^{2}$ how things happen $3 /$ are in this world $\left.{ }^{4}\right)$;

Nke ke ka ba ka qenehela motho ka baka la dithapelo tsa hae" (I will not even pity $1 /$ spare $^{2}$ anyone person because of his prayers $1 /$ pleas $^{2} /$ petitions $\left.^{3 \prime \prime}\right)$;

Efela ruri Chaka o kgutlile moya wa botho o se o le siyo (Indeed, truly, Chaka comes back as a beast ${ }^{1} /$ without a human spirit ${ }^{2}$ );

taba ya hae e le lefu feela, a imameletse hore *nyewe efe le efe, le *phapang efe le efe, a e kgaole (His preoccupation was death only, he decided for himself that whatever the case, whatever the dispute, it will be ended $1 /$ decided $\left.^{2}\right)$;

ka molamu, ka ho bolaya motseki le ya tsekiswang hammoho (by the molamu, by killing the accuser and the accused together ${ }^{1} /$ simultaneously $\left.^{2}\right)$;

o kgutla taba ya hae e le ho lwana ntwa e se nang ho fela (He returns with a purpose, being to fight a never ending fight ${ }^{1} /$ to wage a never ending battle ${ }^{2}$ ) hore ka yona a bolaye dira, a be a bolaye le ba ha hae ka mokgwa oo batho ba ke keng ba o lemoha (so that through it, he kills enemies, and kills his own, in a way that people would not notice $\left.1 / \mathrm{recognise}^{2} / \mathrm{know}^{3}\right)$; boiphetetso bo tshabehang ba pelo ya hae bo ne bo bile bo batla ho mo hlantsha. (the severe ${ }^{1 /}$ frightening ${ }^{2}$ revenge $^{1} /$ vengeance $^{2}$ the terrible wrath of his heart was so intense, it almost drove him crazy $1 /$ to insanity ${ }^{2} /$ nearly drove him crazy ${ }^{3} /$ it almost drove him to insanity $4 /$ is indeed to drive him $\operatorname{mad}^{5}$ ).

It is evident from the analysis of the ST that Mofolo seems to have a preference for longer sentences, in which he does not always simply express a single thought, but he indulges in long descriptions of situations and emotions in his narrative. Although punctuation marks were used by Mofolo as cohesive devices in his descriptions, the translation process was still complicated as participants in the 
workshops struggled to keep track of Mofolo's thoughts-some of the sentences in the original text were five to six lines long. The utterances from Extract 2 marked with an asterisk illustrate this.

Ho le boima *jwang le jwang is literally translated as "it was difficult how and how"; it can be figuratively translated as "it was difficult". The phrase *qetellong ya ditaba's literal translation is "at the end of matters"; it was finally translated as "* the bottom of the matter". The phrase *Kgutlong ya merero is literally translated as " at the return of his plans" but was finally translated as "his heart's desire". *Ho e lata letailane is literally translated as "* to fetch something far off" but was finally translated as "go out of his way to start a fight".

The unit Hore nyewe efe le efe, le phapang efe le efe is literally translated as "which and which case, and which and which quarrel/dispute"; it was finally translated as "whatever the case, whatever the dispute". This unit illustrates another cohesive device Mofolo makes use of, namely parallel descriptions, which also serve to embellish his narrative. Synonyms and repetitions are some other cohesive devices employed by Mofolo, as can be seen in many of the examples above.

Tense and aspect in Sesotho are grammatical categories, as in English. This made the translation into English far easier, as the distinction between past, present and future also exists in Sesotho (also see Baker 108). Mofolo prefers to use a combination of tenses, and includes aspectual differences (completion/non-completion, continuation/non-continuation) as in: Chaka, mohla a tlohang hae ha a baleha (Chaka, on the day he left home in flight) o tlohile e le Chaka (he left [being that] as Chaka) kajeno o kgutla a fetohile hampe (today he returns, [he has changed terribly] as a different person from what he was).

\section{Final translations of the chosen extracts}

The final translation of the two extracts was done by a mother-tongue Sesotho speaker (Nakin). This route was taken as it was realised during the translation process that often a mother-tongue speaker could have sufficient sociolinguistic background to be able to make the final appropriate decisions. Here are the final English translations:

\section{Extract 1:}

"Now tell me what the yearnings of your heart are and that which you desire amongst all things, so that I should lay my staff on it".

"I don't have many desires, my heart longs for my kingship to which I was born. I will lose it just because I have bad luck. I say, you must treat me so that that kingship returns to $\mathrm{me}^{\prime \prime}$.

"I hear, you only want the kingship of your father, do you have no desire apart from that, even a kingship greater than that of your father do you not want it; is it not true that you said so?" 
"No, I do want it. If it is possible that you can make me to become an important king, one that rules independently, one who will cause other less important kings to seek refuge with him, I will be very grateful. But, doctor, please tell me the truth of that which you are able to do; often you doctors let people hope for miracles, those things that you know well that you are not able to do".

"You should believe in me, I will not lie to you. The things of the earth, I believe, of which you have seen only a little, that it should be lived with privileges and favour, with wickedness and with control; and even you, with mercy, you have to part with it as from this day forward; because a good deed is returned by evil. Furthermore, I cannot stay with you much longer; I will work on you, and then I will leave, so that you can remain behind and you yourself labour at that kingship that you yearn for".

\section{Extract 2:}

Chaka, the day he left home in flight, he left as Chaka, he was a person just like all other people, with all the human weaknesses; today he returns as a different person from what he was; only the flesh returned, the outside, with regard to his inner self, his being is left where he came from; he returns with a different spirit and a different humanity. Even before, Chaka was a persistent person in an astonishing way, he was persistent, though it was difficult, until he reached the bottom of the matter, to attain his heart's desire, there was nothing that could stop him from doing what was on his mind; but although it was so, nevertheless he was human: he was not quarrel-poking, he would not go out of his way to start a fight. Today when he sees his siblings killing him for nothing, he notices that his father changes into his enemy, he fled, and when he was there in the wilderness, the core of his being died; today, he comes back with this attitude: "I will just kill anyone I want to kill, whether guilty or not, because that is the rule of the world. I will not even pity any person because of his prayers". Indeed, truly, Chaka came back without a human spirit, his preoccupation was death only, he decided for himself that whatever the case, whatever the dispute, it will be ended by the staff, by killing the accuser and the accused together. He returns with a purpose, being to fight a never ending fight, so that through it, he kills enemies, and kills his own, in a way that people would not notice; the severe vengeance was so intense, it almost drove him to insanity.

\section{Strategies applied during translation}

Translation from one language to another is often characterised by a lack of equivalence at word level, utterance level and even sentence level. The situation becomes even more complicated when translating idioms and fixed expressions. It is therefore crucial that idiomatic expressions and fixed expressions be recognised as such.

Baker's strategies (23) for dealing with non-equivalence at word level were applied in this study, namely, translation by cultural substitution and translation by a more neutral/less expressive word. 
Translation by cultural substitution, of which Baker says: "this strategy involves replacing a culture-specific item or expression with a target-language item which does not have the same propositional meaning but is likely to have a similar impact on the target reader, for instance by evoking a similar context in the target culture" (31).

The use of the word "staff" instead of molamu is an example of cultural substitution, as well as the expression hore hara ntho tsohle ke bee melamu ho sona, translated as "so that I should lay my staff on it". This Sesotho idiom does not have an English equivalent. The phrase ke mpa ke le senyo would be literally translated as "I only am in a sinking place" and was rather translated as "I have bad luck". Mohau o ja mong a wona is literally translated with "grace eats the owner of it"; 'culturally substituted', it can be phrased "a good deed is returned by evil". O ne a pheela leha ho le boima jwang le jwang, literally meaning "although it is difficult how and how", was translated with "although it was difficult". A be a yo fihla qetellong ya ditaba, kgutlong ya merero ya pelo ya hae, translated literally with "until he reached the end of the matters, at the return/direction of the plans of his heart", was figuratively translated as "until he reached the bottom of the matter".

Translation by a more neutral/less expressive word. This strategy was used in translating the phrase pelo ya ka e llela borena ba ka. Literally, it means "the heart of mine it cries for the kingship of mine". It was translated as "my heart longs for my kingship". Also, bo tla mphonyoha was translated with "I will lose it" instead of the literal translation, "it will escape from me".

\section{Conclusion}

During the translation process it became evident that the mapping of the context should always incorporate the socio-cultural context and background of the original text. The translator(s) should never lose sight of the fact that cultural differences have to be accounted for, owing to the fact that these play a crucial role in the translation process. These differences will shape and determine what the eventual translation will look like. In a literary text like Chaka, it could happen that a vast number of archaic words and expressions occur in the ST, which will have to be accommodated in the TT. Motsei (621) underlines the fact that no target text can be functional if it does not take into consideration the "socio-cultural or ethnolinguistic implications of both the source language and the recipient language of the target group(s)".

Based on the experience of translating passages of Chaka, we conclude that a translation is never "right" or "satisfying enough" the first time around: it needs many "re-visits". One would have to go through a process of assessing and re-assessing every possible word in the corpus until one reaches a stage where one is able to decide to conclude one's efforts with a specific word or a description.

Furthermore, one should also favour keeping the content of the translated pieces as near to the original as possible in order to conserve the writer's (in our case, Mofolo's) 
manner and style of writing, so as not to lose the captivating charm of the original text.

During the translation of a ST to a TT, a mother-tongue speaker of the ST and/or TT should be involved in order to incorporate the consideration of the sociolinguistic backgrounds of both texts.

The translation of literary texts should remain a perpetual exercise. It opens up cultures and lives of people one would perhaps never be able to meet, yet, written down on paper, in a language one is able to read, it becomes an almost magical entry into another world, which one would otherwise never have been able to encounter.

Kunene says of the first translation of Chaka by F. H. Dutton in 1931 that he "made an important contribution to world literature, and performed an invaluable service to the dissemination of Sesotho culture through literature. Dutton's translation of Chaka inspired non-Sesotho speaking Africa to heights of creativity as exemplified by the works of Senghor, Badian and Mulikita" (Chaka trans. Kunene xiv). After Dutton, Chaka has been translated into French, again into English, into German, Italian, Swahili and also into Afrikaans.

\section{Works Cited}

Baker, M. In Other Words: A Coursebook on Translation. New York: Routledge, 1992.

Bassnett, S. Translating Literature. Cambridge: D. S. Brewer, 1997.

Casalis, E. The Basutos; or, Twenty-Three Years in South Africa. London: James Nisbet \& Co, 1861.

Dingwaney, A. \& C. Maier, eds. Between Languages and Cultures. Pittsburg: U of Pittsburgh P, 1995.

Mofolo, T. Chaka. Lesotho Orthography. Morija: Sesuto Book Depot, 1925. Chaka. Trans. D. P. Kunene. Essex: Heinemann, 1981.

Motsei, A. S. "Intercultural Communication Problems: Translations from English into Sesotho." Journal for Transdisciplinary Research in Southern Africa 9.3 (2013): 603-23.

Newmark, P. A Textbook of Translation. London: Pergamon, 1988.

Nida, E. A. \& C. R. Taber. The Theory and Practice of Translation. Leiden: E. J. Brill, 1974.

Terran, P. Z. "A New Factor in Translation Theory, an Old Factor in Translation Practice: The Client." Sintagma 4 (1992): 35-45.

Wallmach, K. \& A. Kruger. "'Putting a Sock on It': A Contrastive Analysis of Problem-solving Translation Strategies between African and European Languages." South African Journal of African Languages 19.4 (1999): 276-89. 